of which I had to entrust to the woman in attendance, while I first made an attempt to apply forceps. This failing I tried wersion and brought down both legs quite easily but could not get the body to budge an inch; neither by pressure on the abdomen nor internally, on the head, could a single movement be got. At 9 A.M. I returned home (three miles) to fetch a perforator and a cephalotribe returning about 10 A.M. I again chloroformed the patient as before and perforated easily. Crushing was, however, much more difficult owing to the height of the head in the pelvis ; and though I made several attempts to drag down the head with the cephalotribe in order to get at more distant parts the blades slipped off every time. Finally, at 11.45 A.M. I sent for assistance and Mr. Scudamore kindly came at 1.15 P.M. The cephalotribe, however, was not more useful in his hands than in mine, so that we decided upon embryotomy, for which purpose I was forced to go home again to fetch instruments; among these I brought a scalpel and bistoury but no artery forceps or silk. Embryotomy was, we found, extremely difficult owing to the tightness of the uterine contraction now getting tonic; and as the patient's condition was growing very bad (she had already required three injections of strychnine and brandy) immediate Cæsarean section was decided on, and this I did at 3 P.M. Without waiting for any ritual observance as regards cleansing the abdominal wall, but merely hastily swabbing over with a 1 in 40 carbolic solution, I opened the abdomen. There was, luckily for me, no hæmorrhage from abdominal wall or uterus; the placenta we had noted to be on the posterior wall. The child was rapidly and -easily extracted, the placenta peeled off readily without any loss, and as the liquor amnii had already drained away there was no soiling of the peritoneum. Introducing a carbolised marine sponge into Douglas's pouch I found that there was practically nothing there, so I at once sutured the uterine and abdominal walls, using silkworm gut sutures and my perineum needle for each. A cyanide dressing was then .applied. The patient, who had till now been resting on the mattresses of her bed, was carefully lifted up on to the bed and surrounded with blankets and hot water-bottles; and she slowly rallied again. The operation had lasted almost twenty-five minutes. From the commencement of cephalotripsy the total period of anæsthesia was five and a half hours (from 10 A.M. to 3.30 P.M.), added to which she had had about one hour in the early morning (from 7.30 to 8.30 A.M.). The fœetus, a finely-developed female, weighed fully $9 \mathrm{lb}$. without brains, and was over $20 \mathrm{in}$. in length.

The after-progress of the patient was slow but on the whole satisfactory; constipation and flatulence were the chief drawbacks. The stitches were removed from the wound on Nov. 2nd and it then appeared soundly, healed, but on Nov. 6th the lower angle reopened to give vent to a quantity of broken down, foul-smelling blood-clot; this discharged for a few days only and then the opening slowly closed up. The highest temperature throughout was $100.6^{\circ} \mathrm{F}$. The patient on Nov. 29th was downstairs and getting about again, though not of course performing her household duties.

I have to record my grateful thanks to Mr. Scudamore for his kind and able assistance.

Kingsbury, near Tamworth.

\section{WRITERS' ANGINA.}

BY CHARLES D. MUSGROVE, M.D. EDIN.

THE above title is one which $I$ have adopted to designate certain attacks which have come under my notice as roccurring in individuals who are liable to be called upon to "write against time"-this latter phrase implying more than simply writing rapidly, for, as will be explained shortly, it is when a given amount of writing must be completed in a limited space of time that the factors which are efficient in disturbing the cardiac mechanism are brought into play. I have selected the above title because it signifies both the cause and the character of the disturbance thus induced, and I have felt justified in the use of the term "angina" from the close resemblance which these seizures bear, not only in their outward manifestations but, which is infinitely more important, in their intrinsic nature to the malady known as "angina pectoris." It is the accepted use of the latter term which constitutes one of the chief difficulties in the discussion of cardiac phenomena. It would simplify matters considerably were a writer able to state in a paper of this kind that he intended to regard angina pectoris as a symptom merely; but the term has acquired such an individuality as representative of a distinct clinical entity that for the present it is hopeless to attempt to divest it of this significance, and we must content ourselves with regarding angina pectoris as a malady characterised by certain classical symptoms of which pain in the region of the heart is a predominant one, and having an importance due mainly to its liability sooner or later to end fatally. When, however, we approach the discussion of allied seizures, such as those forming the subject of the present paper, some form of title must be sought which will serve to indicate their nature. "Angina-like attacks" is too clumsy and "angina" suggests itself as at once the most suitable and convenient. If this be prefixed by a term expressive of the conditions under which the attacks occur these latter are furnished with a title which not only indicates their character but also makes clear the distinction between them and angina pectoris properly so called. This distinction is one of vital importance to the safety and comfort of the patient-for his safety in that the cause of the seizures being removed he may avoid the ill-effects liable to ensue from a frequent repetition of the same; and for his comfort in that he may be assured that the attacks from which he suffers are of a curable nature if he will but follow out the directions given to him.

It is only by a minute inquiry into the circumstances under which the attacks take place and the discovery that they occur solely at times when the patient is engaged in hurried writing that we are able to assure him as to the nature of his complaint. The symptoms correspond so closely to those of angina pectoris that it is impossible by a consideration of these alone to eliminate the latter from our diagnosis, and if in addition the patient be at or above middle age the difficulties are still further increased unless the above-mentioned fact in the history of the attacks is inquired into. Observe, however, that I have used the word "solely," for, of course, in a patient who is undoubtedly the subject of angina pectoris genuine angina pectoris may be induced by the effort of writing hurriedly just as by any other form of exertion (which is an entirely different matter). To take a typical case : a business man finds late in the afternoon or evening that he has, say, an hour's correspondence to get through in half that time, and makes a spasmodic attempt to finish it, hurriedly scrawling off one note after another with anxious glances at the clock meanwhile. He is suddenly alarmed by finding bimself seized with a pain in the region of the heart, behind and to the left of the sternum, with a feeling of tightness and oppression about the chest and a sensation as if the heart were going to burst, followed by a number of violent pulsations which one patient graphically described as his heart "turning somersaults," while in some cases the face is covered with a cold sweat. He throws down his pen, leans back in his chair, takes a number of deep breaths, and in a few minutes is comparatively well again, but on resuming his work is again alarmed at finding sooner or later the same train of symptoms repeating themselves.

Before considering the nature of this disturbance, it is necessary to discuss the causes which bring it about. These may be considered under three headings-(1) the concentration of the mental faculties; (2) the posture, and the cramping of the muscles; and (3) the state of the respiration.

To take the last first, a man who is engaged in hurried writing seems to discover, almost unconsciously it may be, that he has not even time to breathe properly, and his respiration tends more and more to consist of short breaths confined to the upper part of the thorax. This condition is further aggravated by the position which he tends to assume, twisting himself round until the left side of his chest is almost in contact with the desk, so that abdominal or deep thoracic respiration is an impossibility. Meanwhile his fingers have become rigid and this rigidity has communicated itself to the muscles of the forearm and thence to those of the upper arm and chest, whilst an observer may soon satisfy himself that even the muscles of the lower extremities have been called upon to contract in the same useless manner. It is evident that as a consequence of the abnormal state of the respiration the right side of the heart must tend to become more or less engorged, while at the same time, owing 
to the amount of muscular rigidity, an extra demand is being made upon that viscus, so that its accelerator nerves are called into action, and this is still more evident when we remember that meanwhile the first of the causes mentioned-viz., the concentration of the mental facultiesis of itself causing an increased rapidity of the heart's action, thus shortening its period of systole and rendering it least effective in dealing with the engorgement of its cavities. This increase in the heart-rate plays an important part in the production of the symptoms, and is still more obvious from the fact that it is impossible to bring these on experimentally by breathing shortly or even holding the breath altogether. This latter procedure may set up a feeling of discomfort in the region of the heart, but so far as I have been able to ascertain it entirely fails to bring about the peculiar sudden pain and other symptoms which I have already described as characteristic of this malady. It seems to me, however, that even these combined causes are not sufficient to account for the climax which occurs and that a satisfactory explanation of the latter is to be found only in the consideration of the state of the coronary arteries at the time. It appears obvious that with the short, ineffective beats of the heart these vessels are unable to furnish the myocardium with a sufficient supply of blood, especially as it is being called upon for an extra amount of work at the time. In the next place it is feasible to suppose that the increasing venosity of the blood due to the inefficient character of the respiration has induced a state of vasomotor constriction in which it is possible that the coronary arteries share. If this be so it is evident that we have to deal with a heart the muscular substance of which is receiving a supply of blood which is not only deficient in quantity but unsuitable in quality and which is consequently in a state of what $\bar{I}$ would term "temporary malnutrition." Hence it is not surprising that when this stage is reached the heart should cease to respond to the demand of the accelerator nerves which must have already been in action for some time and that symptoms of a violent and distressing nature should ensue. In introducing this element of vaso-motor spasm of the coronaries I am fully aware that it is a subject upon which much scorn has been cast and writers have not been infrequently reminded that they had better have left it out of their calculations until something definite was known about it. This, however, it appears to me, would have the effect of barring our way to any further knowledge of the subject, for it is difficult to conceive that any data can be obtained on the point by experimental investigation on account of the impossibility of approaching the structures concerned. Bearing in mind the fact that the coronary arteries represent practically the sole supply of blood to the heart substance, it certainly appears improbable that these vessels should be devoid of any controlling agent in regard to the amount of blood passing through them, and that their tension should be dependent entirely upon that within the aorta; and the only probable and efficient factor which is conceivable to my mind is that of vaso-motor influence. That this influence has suggested itself to the minds of writers on allied subjects is evident from the not infrequent mention of it in the literature of cardiac disease. Dr. G. W. Balfour, ${ }^{1}$ for instance, remarks in connexion with angina pectoris : "There is every reason to suppose that the arterial spasm which is so evidently the cause of local asphyxia and which takes so prominent a share in the production of an attack of angina vaso-motoria occasionally invades the heart either as part of a general or it may be as a distinctly local affection, and that this is a very possible cause of those anginal attacks where no other seems obvious." Sir R. Douglas Powell" also in an article on the myocardium in "Allbutt's System of Medicine," says: "There is every reason to believe that the coronary arteries, like other vessels of equal size and equally endowed with muscular tissue, are liable to spasmodic contraction." In the case of the malady we are now considering this element would certainly appear to furnish a link without which an analysis of the symptoms is incomplete. It is advisable in passing to emphasise the fact that vasomotor spasm is not suggested here as a direct cause of pain in itself but as a factor in the production of that temporary change in the nutrition of the myocardium which I have

1 The Senile Heart, 1894

2 Allbutt's System of Medicine, vol. $v$. 1898: Diseases of the Myo= cardium. suggested as contributing lately to the crisis of which pain is a predominant symptom.

We are now in a position to discuss the nature of this crisis and the position which it occupies in the scale of cardiac phenomena-its relationship to palpitation with its attendant discomfort on the one hand and angina pectoris with its acute pain and anguish on the other. From simple palpitation the diagnosis is easily made from the peculiar nature and onset of the symptoms. From angina pectoris, on the other hand, the differentiation is one of deep interest; the difficulty lies in the circumstance that the literature of angina is "confusion worse confounded," owing to the fact that the distinction has so frequently been made from a superficial comparison of symptoms. Some, for instance, would settle the matter by calling it "false angina"; but here again each author appears to have his own method of separating true from false, deciding the question. by the presence or absence of pallor of the face, the com. pressibility of the pulse, the sense of impending death, the. age of the patient, and so on. If, however, we confine our attention to those authors, such as Dr. G. W. Balfour, who discuss the subject of angina from the standpoint of its intrinsic nature instead of from mere superficial resemblances, the question quickly resolves itself.

Dr. Balfour appears to trace the progress of an attack of angina pectoris in three stages-(1) a permanent malnutrition of the heart-substance; (2) a call upon the augmentor nerves of the heart to which the heart fails to respond; and (3) a secondary affection of the associated spinal nerves resulting in pain. Now, the explanation which $I$ have offered above of the attacks which I have termed "writers" angina" is that the respiratory embarrassment, the muscular rigidity, and the mental concentration have combined to hurry the heart and to render it ineffective and thus to deprive the coronary arteries of their due amount of blood-this. possibly being further diminished by a vaso-motor spasm of these vessels-and that the heart is consequently in a state. of "temporary malnutrition." The accelerator nerves of the heart have of course already been called upon to act, and my point of view is that as this temporary malnutrition is. established there must come a time when the heart ceases to respond to the demand of the augmentor nerves and that the crisis of the attack is thereby precipitated. In angina pectoris the heart is unable to respond to the call of the augmentor nerve ; in "writers' angina" it ceases to do so. But the intrinsic difference lies in the permanent nature of the malnutrition in the former and its temporary character in the latter, due to a distinct and removeable cause, to which our treatment must be directed. This treatment consists in explaining to the patient the why and the wherefore of his malady and in insisting upon his engaging in his correspondence deliberately and quietly. Furthermore, he must be instructed as to the way in which he is to sit, so as to prevent him assuming the cramped and twisted position into which he is so liable to lapse, as already described. The simple mancurre of crossing the right leg over the left renders this attitude almost impossible, and as a consequence enables the writer to breathe more deeply, so that by this means alone we are enabled to eliminate one or two of the most important factors concerned in the onset of the symptoms.

It only remains to consider the ill-effects of this condition.

1. In those who are otherwise healthy a state of cardiac irritability is apt to be induced and to be kept up so long as any repetition of the attacks takes place. As yet I have not been able to satisfy myself that dilatation of the heartwall follows as a consequence of these attacks. It is not unreasonable, however, to infer that such a result is only too likely to occur, seeing that the two chief elements concerned in its causation are present-viz., (a) over-distension of the cavities of the heart and (b) diminished power of resistance due to temporary anæmia in the muscular substance, while it seems only too probable that the substance will sooner or later tend to give way before the recurring outbursts of pressure to which it is subjected.

2. With regard to those who are already suffering from dilatation I can affirm from observation that the condition is aggravated by the attacks. One case in particular which I had the opportunity of closely watching illustrated this. It was that of a medical man who, after an attack of acnte rheumatism, suffered from symptoms of a cardiac affection, diagnosed by one of the leading authorities as dilatation. With treatment the patient improved to such an extent that he could take moderate exercise without distress, but any 
attempt to write hurriedly invariably brought on an attack such as $I$ have described above, followed by symptoms which clearly pointed to an aggravation of the cardiac mischief, more particularly to an increase of the dilatation of the right cavities.

3. In those who are the subjects of valvular disease there is considerable danger of increasing the cardiac trouble. One case illustrated this in a marked manner. The patient was a young man whom I had previously treated for mitral regurgitation. He had steadily improved, competency was established, and the amount of regurgitation had become comparatively slight. One evening he was called upon to finish a number of documents in a hurry; he suffered, as be was doing them, from his heart in the manner which $I$ have described above and on the next day he felt too ill to go out. On my being called to see him I found him in a half-fainting condition with a scarcely perceptible pulse but with a pronounced apex-beat, a markedly accentuated pulmonary second sound, and other evidences of considerable mitral regurgitation. Such a result occurring suddenly seems explicable only on the hypothesis of an interference with the blood-supply to the myocardium, the condition which $\mathrm{I}$ have described above as temporary malnutrition. It may be argued that the latter is of too short a duration to have any appreciable influence on the muscular tissue of the organ, but it must be remembered (a) that the regurgitation itself would in its turn tend to keep up the diminution in the amount of blood passing through the coronary arteries, and (b) that pathological changes in the left ventricle taking place as the result of anæmia of its substance are apt to occur with surprising rapidity. While I do not wish to infer that the changes in this case were of a permanent nature still it is feasible to suppose that a serious weakening either of the papillary muscles or of the fibres surrounding the mitral orifice had occurred, with the result above described.

4. The dangers of this condition in middle-aged or elderly persons, especially those presenting any signs of atheroma, are too obvious to need more than a mere mention. In such cases it is of the utmost importance to warn the patients against the harm of writing in a hurry. They are not likely to injure themselves by hill-climbing or athletics and they have probably learned by experience that it is better for them not to run upstairs or hurry to catch trains, but it has never dawned upon them that in their daily correspondence they are liable to a form of exertion equally dangerous both in its immediate and its more remote effects.

Penarth, South Wales.

\section{POST-DIPHTHERITIC PALST OF THE OCULAR MUSCLES.}

BY J. PORTER PARKINSON, M.D., M.R.C.P. LOND., PHY IIIAN TO OUT-PATIETTS, NORTH-EASTERN HOSPITAL FOR CHILDREN LATE MEDICAL REGISTRAR TO WESTMINSTER HOSPITAL; AND

SYDNEY STEPHENSON, M.CH., F.R.C.S. EDIN., ') PHYHALMIC SURGEON, YORTH-EASTERN HOSPITAL YOR CHIIDREX, ETC.

From time to time cases have been recorded where palsy of the extrinsic ocular muscles has followed diphtheria. A glance at the scattered literature shows that the condition may involve one or several muscles and that it may or may not be associated with paresis of accommodation. For instance, in the cases of Henoch and of Heinz the external recti suffered; in Rumpf's patient the internal recti were paralysed; and in Kraus's case the superior oblique of one side was affected. The levator palpebra superioris may be attacked either by itself (Callan) or along with other muscles (Benson and Ewetzky). Extensive paralyses amounting to ophthalmoplegia externa have been noted by Donders, Hasche, Uhthoff, and Mendel among other writers. It is scarcely necessary to say that these affections may occur as a sequel to diphtheria of any part of the body. Dr. W. Gayton ${ }^{1}$ recorded a case where diphtheria of the genital organs was succeeded some three weeks later by palatal paralysis and " marked strabirmus."

'The general view that post-diphtheritic paralysis of the extrinsic ocular muscles is infrequent is endorsed by Gowers in his widely-quoted "Manual of Diseases of the Nervous

1 The Lancet, May 26th, 1894.
System" (1888). On page 178 of that invaluable work it is stated tbat " a rare cause of palsy of the external muscles is diphtheria." Despite this expression of opinion from so distinguished an authority our experience leads us to believe that as a matter of fact such cases are not very uncommon, although they may not often be brought for treatment to hospital unless the eye condition is complicated by some more serious and striking form of paralysis. In support of this view we are able to quote two recent cases which have fallen under our notice in consecutive months at the NorthEastern Hospital for Children, Shoreditch.

CASE 1.-A girl, aged nine years, was admitted to the hospital under one of us on April 13th, 1898. Seven weeks prior to coming under notice she was treated at home for what was described as "an ulcerated throat." During the last two or three weeks the mother had noticed that the child experienced difficulty both in swallowing and in breathing and that fluids taken by the mouth were apt to return through the nose. The mother further stated that for the last week the sight had been so bad that the patient "could not read print at all." On admission, the child was found to be anæmic with wellmarked nasal phonation; the soft palate was immobile on phonating, while on being touched no reflex was elicited. There was slight ptosis. The pupils were large and equal; they reacted sluggishly to light and not at all to accommodation. The extrinsic eye muscles were paralysed except the external recti and (possibly) the superior oblique. There was therefore a condition of crossed diplopia. Refraction (estimated by direct ophthalmoscopic examination) wasright eye $2 \mathrm{D}$. and left eye $3 \mathrm{D}$. of hypermetropia. The fundi were normal except for the existence of a congenital crescent (Fuchs) at the lower part of each optic disc. The gait was weak with a tendency to sway and fall ; the kneejerks were absent. The movements of the diaphragm on respiration appeared to be deficient; respiration was markedly thoracic. The heart was normal; the pulse was 100, regular, and compressible. The urine was 1020 , acid, with no sugar or albumin ; there was a slight deposit of phosphates. The patient was kept in bed, placed upon full diet and port wine, and given half a drachm of Waston's syrup thrice daily. She gradually improved. The ptosis disappeared after she had been a week in hospital and by this time the diplopia had lessened and slight movements of the affected eye muscles could be made out. Improvement continued until May 13th when she was discharged on account of infectious disease in the ward. Some five months later (Oct. 19th, 1898) the child was brought to the hospital for examination. The gait was strong; the knee-jerks were present, and the palatal reflex was normal. The pupils were equal and contracted both to light and to accommodation. There was no strabismus and binocular vision was present. Amplitude of accommodation was-right eye $12 \mathrm{D}$. and left eye $13 \mathrm{D}$

CASE 2.-A boy, aged five years, was brought to the hospital on May 18th, 1898, suffering from a strabismus said to have been present for one week only. His mother's story was that at the beginning of April the child developed a sore-throat associated with feverishness and swollen cervical glands. On May 11th she noticed that his left eye turned inwards and further inquiry brought out the fact that the lad had "talked thick" for about five days before the strabismus came on. Upon examination there was a convergence of the left eye measuring on the perimeter $30^{\circ}$, while the so-called secondary deviation of the other eye was $40^{\circ}$ or more. Owing to the tender age of the child the diplopia that was present could not be investigated with any satisfactory result. There was a distinct reduction of the outward morement of the squinting eye. Letters of No. 1 Jaeger could be read. The fundi were normal. The gait was unsteady and there was a tendency to fall when the patient attempted to run or to turn quickly; the knee-jerks were absent. The palate was normal; the voice was not nasal. The pulse was 100 and regular. The urine was free from albumin. The child was thin, white, and looked rather ill. On June 1st ore drachm of Parrish's syrup was ordered three times a day. When seen a week later (June 8th) the strabismus had disappeared but the knee-jerks were still wanting. On June 20 th the latter had returned, although the patient was stated to be still "weak on his legs." He eventually made a complete recovery.

From the foregoing remarks it will be noticed that one of our patients suffered from paresis of the external rectur without affection of accommodation, whereas the otber 